\title{
Selection strategies considering varietal differences with respect to egg characters of mulberry silkworm, Bombyx mori L.
}

\author{
Md. Kamrul Ahsan \\ Associate Professor, Department of Zoology, Rajshahi University, Rajshahi-6205, Bangladesh
}

\begin{abstract}
The genotypic variability and correlation coefficients were studied in 27 indigenous multivoltine varieties of mulberry silkworm, B. mori L. for six egg characters. The genotype was highly significant for all the characters under studied. Least difference between genotypic and phenotypic coefficient of variation were observed. Majority of the characters showed high heritability comparing with dead egg percentage. Furthermore Unfertilized egg percentage showed high genetic advance together with high heritability but HP and EW showed high heritability and low genetic advance. These indicate the importance of additive and non-additive gene effect of these characters respectively. Total number of egg laid by female, hatching percentage, and blue egg percentage showed both positive and negative significant correlation to each other at both the phenotypic and genotypic levels. The results suggest that these characters specially total number of egg laid by female, blue egg percentage and unfertilized egg percentage appeared as importance in selection programme for genetic gain in $B$. mori.
\end{abstract}

Key words: genetic variability, correlation, B. mori.

\section{Introduction}

Silkworms are well known industrial insects which produce natural silk. More than 3000 silkworm strains are available all over the world due to various ongoing breeding programmes (Rao et. al., 2006; Thangavelu et. al., 2003; Nagaraju, 2002). These are univoltine, bivoltine and multivoltine. In tropical countries like Bangladesh, multivoltine silkworm strains play important role in the production of silk. There are about fifty indigenous multivoltine varieties maintained at the Germplasm Bank of Bangladesh Sericulture Research and Training Institute (BSRTI), Rajshahi. These varieties being highly resistant to diseases were very much popular among the farmers of Bangladesh. But the qualitative and quantitative traits of these varieties including silk yield and quality of silk fibre are very poor. To overcome these difficulties and to boost up silk production in the country, high yielding developed varieties of silkworm were introduced in Bangladesh for commercial rearing.

Genetic variability is a prerequisite for an effective selection of any economically important plant and animal species and a critical survey of genetic variability is essential aiming at developing high yielding varieties (Akanda et. al., 1998). In silkworm breeding numerous traits are considered as important for improving them to increase the profit of silk producers and other sections of sericulture industry. Reproductive traits are

\begin{tabular}{llll}
\hline 1. Nistari & 2. Nistri (M) & 3. Nistri (P) & 4. Nistri (KP)M \\
5. Nistri (ISK) & 6. Nistri (O) & 7. Nistri (L) & 8. Nistri (IL) \\
9. Nistri (K)P & 10. Nistri (DC) & 11. BSR-3(M) & 12. BSR-3(P) \\
13. BSR-10(M) & 14. BSRI-801 & 15. BSRI-802 & 16. BSRI-83/1 \\
17. BSRI-83/2 & 18. BSRI-83/3 & 19. BSRI-85/1 & 20. BSRI-85/2 \\
\hline 21. BSRI-85/3 & 22. Urboshi-1 & 23. Urboshi-2 & 24. Urboshi-3 \\
25. Urboshi-4 & 26. $\mathrm{M}_{2} \mathrm{P}_{2}$ & 27. O5 &
\end{tabular}

The eggs of $F_{1}$ hybrids were brushed (3dfls for each genotype) in a randomized design with three replications each. The rearing was conducted in considered important by egg producers. These traits jointly or singly influence the egg production (Reza \& Rahman, 2005; Zhao et al., 2007; Ahsan \& Rahman, 2008). A great diversity of polyvoltine silkworm Bombyx mori L. must exist globally, by considering the fact that a large number of silkworm breeds are already evolved by selection or cross breeding and also some of the tropical countries allowed individual farmers to produce silkworm eggs (Kumaresan et al., 2007). The selection of best genotypes depends on a of characters (Ahsan and Rahman, 2010). Therefore, a clear understanding and knowledge of association and contribution of various reproductive components is essential for any selection programme aimed at egg production.

Hence, the present study was undertaken to estimate the genetic variation for six important egg characters and correlations among them at phenotypic and genotypic levels for designing suitable breeding programmes.

\section{Materials and methods}

The materials for this experiment comprised of twenty seven indigenous multivoltine varieties of mulberry silkworm, B. mori. These parents were obtained from the Germplasm Bank maintained at the Bangladesh Sericulture Research and Training Institute (BSRTI), Rajshahi. The names of the varieties are:

the rearing house No. 2 of the BSRTI, Rajshahi. Scientific technology of silkworm rearing was followed according to Krishnaswami (1978) and Rahman (1983). Data recorded for this study 
were: total number of eggs laid per female (TEL), hatching percentage (HP), blue egg percentage (BEP), unfertilized egg percentage (UEP), dead egg percentage (DEP) and egg weight (EW). The collected data were analyzed successively for estimating genetic variability, heritability and genetic advance according to the formula described by Burton \& De Vane (1953), Burton (1952), Hanson et. al. (1956), Lush (1949) and Johnson et al. (1955). The phenotypic and genotypic correlations were calculated according to the formula as follows:

$r\left(x_{1} x_{2}\right)=\frac{\operatorname{COV}\left(x_{1} x_{2}\right)}{\sqrt{V\left(x_{1}\right) V\left(x_{2}\right)}}$

\section{Results and discussion}

Overall range, mean with standard error, mean square and component of variations for different characters are presented in Table 2. The mean square in the table showed that variations among genotypes were highly significant $(P<0.001)$ for all the characters studied indicating that the varieties possess a wide range of genetic diversity and these could be suitable for breeding purposes. Ahsan et al. (2000) reported that varietal differences with respect to egg, larval and cocoon characters were found in $B$. mori. Similar results on varietal diversity have also been substantiated by the findings of Reza \& Rahman (1996) and Ahsan \& Rahman (2008). Phenotypic variances $\left(\sigma^{2} p\right)$ were generally greater than their corresponding genotypic $\left(\sigma^{2} g\right)$ or environmental variances $\left(\sigma^{2} e\right)$ in all the cases. All the characters showed least difference between genotypic $\left(\sigma^{2} g\right)$ and phenotypic coefficient $\left(\sigma^{2} p\right)$ of variation suggesting less influence of environment on these characters but they are under strong genotypic control (Table 1).

Table 1. Range, mean with SE, mean square and components of variance of different characters of hybrids of silkworm, B. mori L.

\begin{tabular}{|c|c|c|c|c|c|c|c|}
\hline Characters & Range & Mean & SE & MS & $\mathrm{P}$ & G & E \\
\hline$\overline{\text { TEL }}$ & 300.67-519.33 & 418.77 & $\overline{3.41}$ & $11279.72^{\star \star \star}$ & 3772.03 & 3753.85 & 18.18 \\
\hline HP & 71.68-83.98 & 77.96 & 0.73 & $30.51^{\star \star \star}$ & 10.71 & 9.90 & 0.81 \\
\hline BEP & $5.62-14.85$ & 9.56 & 0.42 & $16.85^{\star \star \star}$ & 5.79 & 5.53 & 0.27 \\
\hline UEP & $0-13.86$ & 5.69 & 0.61 & $36.68^{\star \star \star}$ & 12.60 & 12.04 & 0.56 \\
\hline DEP & $0-6.43$ & 3.05 & 1.61 & $7.13^{\star \star \star}$ & 2.96 & 2.09 & 0.88 \\
\hline EW & $0.31-0.79$ & 0.439 & 0.003 & $0.016^{\star \star \star}$ & 0.005 & 0.005 & .000015 \\
\hline
\end{tabular}

*** Significant at $0.1 \%$ level, $\mathrm{P}=$ Phenotypic variance, $\mathrm{G}=$ Genotypic variance, $\mathrm{E}=$ Environmental variance.

The genetic parameters, phenotypic $\left(\mathrm{CV}_{\mathrm{p}}\right)$, genotypic $\left(\mathrm{CV}_{\mathrm{g}}\right)$ and environmental $\left(\mathrm{CV}_{\mathrm{e}}\right)$ coefficient of variability, heritability $(\mathrm{H})$, genetic advance (GA) and genetic advance as percentage of mean (GA\%) were estimated and presented in Table 2. The highest phenotypic and genotypic coefficient of variation was observed in UEP and the lowest in HP whereas the highest environmental co-efficient of variation was recorded in DEP and the lowest in EW. The inconsistent results of environmental co-efficient of variation for different characters indicated that the genotypicenvironment interactions had a great influence on these characters. The significance of genotypic environment interaction in $B$. mori has also been recognized. In the present experiment the highest heritability was obtained for EW followed by TEL, UEP, BEP, HP and the lowest for DEP. Unfertilized egg percentage (UEP), BEP and EW showed very high heritability together with high phenotypic $(\mathrm{CVp})$ and genotypic $(\mathrm{CVg})$ coefficient of variability. Ahsan et al., (2010) reported high heritability together with high phenotypic and genotypic coefficient of variability of filament length and estimated cocoon yield per 100 dfls. The results of Ahsan \& Rahman (2008) is similar with the present findings who reported a high heritability coupled with high phenotypic and genotypic coefficient of variability for total eggs laid by female.

The estimates of genetic advance expressed as percentage of mean showed a wide range from 7.99 for HP to 122.85 for UEP. Unfertilized egg percentage (UEP) expressed the highest genetic advance together with high heritability. It indicated the importance of additive gene effects of these characters (Rahman, 1984; Reza et. al., 1993, Hasan et al., 2011). It also indicated a wide rage of genetic diversity which could be used in a breeding programme and phenotypic selections of these characters would be effective. Rao (1997) reported that the characters such as, single shell weight (in bivoltine) and single cocoon weight, single shell weight and filament length (in 
multivoltine) showed high heritability with high genetic advance.

High heritability does not always give high genetic advance as was indicated by Johnson et al., (1955). High heritability but relatively low genetic advance was observed for the characters such as HP and EW. It suggested limited scope for manipulation of these characters. These could be due to non-additive gene action which includes dominance and epitasis (Ahsan \& Rahman, 2008). In such situations, progeny testing and recurrent selection might be helpful to improve these traits (Rahman, 1984; Rao, 1997; Ahsan \& Rahman, 2010; Hasan et al., 2011).

Table 2. Phenotypic (CVp), genotypic (CVg), and environmental (CVe) coefficient of variation, heritability $\left(\mathrm{h}^{2}\right)$, genetic advance (GA) and genetic advance as percentage of mean (GA\%) for different characters of hybrids of silkworm, B. mori L.

\begin{tabular}{lllllll}
\hline Characters & CVp & CVg & CVe & $\mathrm{h}^{2}$ & GA & GA\% \\
\hline TEL & 14.67 & 14.63 & 1.02 & 99.52 & 125.91 & 30.07 \\
HP & 4.20 & 4.04 & 1.15 & 92.46 & 6.23 & 7.99 \\
BEP & 25.18 & 24.59 & 5.42 & 95.37 & 4.73 & 49.48 \\
UEP & 62.39 & 60.98 & 13.19 & 95.53 & 6.99 & 122.85 \\
DEP & 56.41 & 47.40 & 30.58 & 70.61 & 2.50 & 81.96 \\
EW & 16.39 & 16.38 & 0.87 & 99.81 & 0.15 & 34.17 \\
\hline
\end{tabular}

The phenotypic $\left(r_{p}\right)$ and genotypic $\left(r_{g}\right)$ correlations between all pairs of characters studied in this investigation analysed have been shown in Table 3. In the present study TEL, HP, DEP and EW showed positive correlations to each others. Of these correlations TEL, HP and HP, EW pairs associations were significant at phenotypic and genotypic levels. Significant positive correlation of BEP was found with UEP at both the levels. But the characters TEL, HP, DEP and EW showed negative correlations with BEP and UEP. Majority of these correlations were significant except BEP, DEP and UEP, EW pair associations at both the levels and UEP, DEP only at genotypic level. Ozdzenska \& Kremky (1987) reported both positive and negative correlations between different component characters. They reported high positive correlations between survival rate and cocoon yield, and a negative correlation between hatchability and number of eggs per gram in B. mori. Singh et. al. (1994) reported the same results between shell weight and fecundity. Chatterjee \& Pradeep (2003) investigated the relationship between yield potential and molecular markers in silkworm. Similar results on different characters of silkworm were also reported by Mistri and Jayaswal (1992), Singh et al. (1994), Ahsan \& Rahman (2008), and Ahsan \& Rahman (2010).

In general, genotypic correlation coefficients $\left(r_{g}\right)$ were greater in magnitude compared to those of phenotypic correlations $\left(r_{p}\right)$. These low phenotypic correlations could be due to a modifying effect of environments of the association of characters at genotypic level (Rahman, 1984). Similar results were also reported by Siddiqui et al., (1992) in Antheraea mylitta and Ahsan \& Rahman (2008 \& 2010) in B. mori.

Table 3. Phenotypic $\left(r_{p}\right)$ and genotypic $\left(r_{g}\right)$ correlation coefficients between all pairs of characters of hybrids of silkworm, B. mori L.

\begin{tabular}{lllllll}
\hline Variables & & TEL & HP & BEP & UEP & DEP \\
\hline HP & $r_{p}$ & $0.7423^{\star \star \star}$ & & & & \\
BEP & $r_{g}$ & $0.7785^{\star \star \star}$ & & & & \\
& $r_{p}$ & $-0.4851^{\star \star}$ & $-0.8568^{\star \star \star}$ & & \\
UEP & $r_{g}$ & $-0.4993^{\star \star}$ & $-0.8572^{\star \star \star}$ & & \\
& $r_{p}$ & $-0.7497^{\star \star \star}$ & $-0.7601^{\star \star \star}$ & $0.3971^{\star}$ & & \\
DEP & $r_{g}$ & $-0.7732^{\star \star \star}$ & $-0.7698^{\star \star \star}$ & $0.3924^{\star}$ & & \\
& $r_{p}$ & 0.1739 & 0.0057 & -0.0835 & -.2274 & \\
EW & $r_{g}$ & 0.1982 & 0.134 & -0.184 & $-0.3375^{\star}$ & 0.0356 \\
& $r_{p}$ & 0.0752 & $0.368^{\star}$ & $-0.4777^{\star \star}$ & -0.1408 & 0.0468 \\
\hline
\end{tabular}

Genetic parameters and characters association of the present study revealed that these characters had the inherent association to each other specially the characters, TEL, HP, BEP and UEP, and thus implying prime importance to include them in selection programmes for genetic gain in B. mori. 


\section{Reference}

Ahsan, M.K. \& Rahman, S.M. 2008. Genetic variability and correlation analysis in hybrids of silkworm, Bombyx mori L. for egg characters. Univ. j. zool. Rajshahi Univ. 27: 13-16.

Ahsan, M. K. \& Rahman, S. M. 2010. Genetic variation of some quantitative traits in ten exotic varieties of silkworm, Bombyx mori L. Univ. j. zool. RajshahiUniv. 29: 69-71.

Ahsan, M.K., Rahman, S.M. \& Ali, I.A. 2000. Variability of some quantitative traits in the hybrids of silkworm, Bombyx mori L. Univ. j. zool. Rajshahi Univ. 19: 20-24.

Ahsan, M.K., Rahman, S.M. \& Haque, M.T. 2010. Genetic variability, heritability and correlation analysis for some characters in hybrids of the mulberry silkworm, Bombyx mori L. J. Life Earth Sci. 5: 43-46.

Akanda, M. A. L., Alam, M. S. \& Uddin, M. M. 1998. Genetic variability, correlation and path analysis in composite maize. Bangladesh J. Agril. Res. 23(1): 107-113.

Burton, G.W. 1952. Quantitative inheritance in grass. Proc. $6^{\text {th }}$ Inter. Grassland Cong. 1: 277-283.

Burton, G.W. and De Vane, E.H. 1953. Estimating heritability in tall fescue (Fescuta arundinacae) from replicated clonal meteriasa. Agron. J. 45: 579-604.

Chatterjee, S. N. \& Pradeep, A. R. 2003. Molecular markers (RAPD) associated with growth, yield, and origin of the silkworm, Bombyx mori L. in India Russian Journal of Genetics. 39(12): 1365-1377.

Hanson, C. H., Robinson, H. F. and Comstock, R. E. 1956. Biometrical studies of yield in segregation populations of Korean lespedeza. Agron. J. 48: 268-272.

Hasan, M.A., Rahman, S.M. \& Ahsan, M.K. 2011. Genetic variability, correlation, path analysis and construction of selection index in mulberry silkworm, Bombyx mori L. I. Genetic variability. Univ. j. zool. Rajshahi Univ. 30: 33-36.

Johnson, H.W., Robinson, H.F. \& Comstock, R.E. 1955. Estimates of genetic and environmental variability in soyabean. Agron. J. 47: 314-318.

Krishnaswami, S. 1978. New Technology of silkworm rearing. Central Silk Board, India. 23pp.

Kumaresan, P., Sinha, R.K. \& Urs, S.R. 2007. An analysis of genetic variation and divergence in Indian tropical polyvoltine silkworm, Bombyx mori L. genotypes Caspian J. Env. Sci. 5(1): 11-17.

Lush, J. L. 1949. Heritability of quantitative characters in farm animals. Heriditas (suppl.). 35: 256-261.
Mistri, P.K. \& Jayaswal, K.P. 1992. Studies on phenotypic correlations between some economic traits of silkworm, Bombyx mori L. Bull. Seric. Res. 3: 26-29.

Nagaraju, J., 2002. Application of genetic principles for improving silk production. Current Sci 83(4): 409-414.

Ozdzenska, B. \& Kremky, J. 1987. Estimation of heritability and genetic, phenotypic and environmental correlations in outbreed population of mulberry silkworm, Bombyx mori L. Sericologia 27: 633-638.

Rahman, S.M. 1983. Technology of mulberry silkworm rearing suitable for the climatic condition in Bangladesh. Reshom 1: 71-79.

Rahman, S.M. 1984. Studies on the genetic improvement of eri silkworm, Philosamia ricini. Boisd of Bangladesh. Ph.D thesis, Department of Zoology, Rajshahi University. 419pp.

Rao, C.G.P., Seshagiri, S.V., Ramesh, C., Ibrahim Basha, K., Nagaraju, H. \& Chandrashekaraiah. 2006. Evaluation of genetic potential of the polyvoltine silkworm (Bombyx mori L.) germplasm and identification of parents for breeding programme. J. Zhejiang Univ. Sciences B. 7(3): 215-220.

Rao, P.R.T. 1997. Genetic architecture and gene action in Bombyx mori L. Ph.D thesis, Department of Zoology, University of North Bengal, Darjeeling-734430, India. 191pp.

Reza, A.M.S. \& Rahman, S.M. 2005. Genetic parameters of some yield and yield contributing traits in silkworm, Bombyx mori L. Univ. j. zool. Rajshahi Univ. 24: 55-58.

Reza, A.M.S. \& Rahman, S.M. 1996. The genetic variability, heritability and genetic advance in silkworm, Bombyx mori L. Bangladesh J. Agri.21: 1-6.

Reza, A.M.S., Rahman, M.S. \& Rahman, S.M. 1993. Studies on the variation of some larval traits in different breeds of silkworm, Bombyx mori L. Univ. j. zool. Rajshahi Univ. 12: 21-24.

Siddiqui, A.A., Sinha, M., Kumar, A., Bajpayi, C.M. \& Sinha, S.S. 1992. Selection of better genotypes through pathcoefficient analysis in segregating generation of Antheraea mylitta D. Sericologia. 32(2): 239-245.

Singh, T. Chandrashekharaiah \& Samwo, M.V. 1994. Selection strategies in relation to correlation and heritability in the silkworm, Bombyx mori L. Bull. Seric. Res. 5: 37-41.

Thangavelu, K., Sinha, R.K. \& Mohan, B. 2003. Silkworm germplasm and their potential use, proceeding of mulberry silkworm breeder's summit. Hindupur, India. p. 14-23.

Zhao, Y., Chen, K. \& He, S. 2007. Key principles for breeding spring-and-autumn using silkworm varieties: from our experience of breeding $873 \times 874$. Caspian J. Environ. Sci. 5: 57-61. 